\title{
Preparation and characterization of polyacrylonitrile membranes modified with polyelectrolyte deposition for separating similar sized proteins
}

\author{
Filiz Yasar Mahlicli ${ }^{a}$, Sacide Alsoy Altinkaya ${ }^{\mathrm{a}, *}$, Yilmaz Yurekli ${ }^{\mathrm{b}}$ \\ a Department of Chemical Engineering, Izmir Institute of Technology, Gulbahce Kampusu, 35430, Urla, Izmir, Turkey \\ ${ }^{\mathrm{b}}$ Department of Chemical Engineering, Ondokuz Mayıs University, Kurupelit Kampusu, 55139, Kurupelit, Samsun, Turkey
}

\section{A R T I C L E I N F O}

\section{Article history:}

Received 10 October 2011

Received in revised form

10 May 2012

Accepted 11 May 2012

Available online 22 May 2012

Keywords:

Ultrafiltration

Polyelectrolytes

Polyacrylonitrile

Myoglobin

Lysozyme

\begin{abstract}
A B S T R A C T
One of the challenges faced by ultrafiltration membranes is to separate proteins with a small difference in their molecular weights. Recently, some researchers tried to overcome this problem by using charged membranes. This study examined the use of layer by layer deposition of polyelectrolytes on the chemically-modified polyacyronitrile membrane to increase the selectivity of the ultrafiltration. The membranes were prepared by wet-phase inversion technique and polyethylenimine (PEI) and alginate (ALG) were chosen as cationic and anionic polyelectrolytes for the modification of the surfaces. Sieving coefficient data were obtained with myoglobin and lysozyme as model proteins. The influences of solution $\mathrm{pH}$, ionic strengths of the protein and polyelectrolyte solution and the number of polyelectrolyte bilayers on both selectivity and throughput were investigated. The highest selectivity and throughput were achieved with the 1-bilayer PEI-ALG coated polyacrylonitrile (PAN) membrane. Increasing the number of coating bilayers or the ionic strength of the protein solution or adding salt into the polyelectrolyte coating solution decreased both the maximum selectivity and throughput of the modified membranes.
\end{abstract}

(c) 2012 Elsevier B.V. All rights reserved.

\section{Introduction}

Previously, ultrafiltration systems have been limited to separating proteins that differ in molecular mass by at least a factor of 10 . In recent years, it was shown that charged ultrafiltration membranes can overcome this limitation, since the process in this case involves both size and charge-based exclusion. Several studies have demonstrated that electrostatic interactions between the proteins and membrane play an important role in obtaining high-resolution separations. It was recognized that significant improvements in the ultrafiltration of the proteins can be obtained by controlling the $\mathrm{pH}$ and ionic strength of the protein solution. Pujar and Zydney (1994) found that the transmission of bovin serum albumin (BSA) through a $100 \mathrm{kDa}$ membrane increased by more than two orders of magnitude as the salt concentration was increased from $1.5 \mathrm{mM}$ to $150 \mathrm{mM}$ [1]. This was attributed to the increased electrostatic exclusion of the charged BSA from the membrane pores at low ionic salt concentration. By careful adjustment of $\mathrm{pH}$ and conductivity, Saksena and Zydney (1994) found a significant increase in the selectivity for fractionation of BSA from immunoglobulin G [2]. Similarly, Rabiller-Baudary et al. (2001) also reported that, with an increase in ionic strength, lysozyme transmission rates through

\footnotetext{
* Corresponding author. Tel.: +90 2327506658; fax: +90 2327506645 .

E-mail address: sacidealsoy@iyte.edu.tr (S. Alsoy Altinkaya).
}

zirconia and grafted membranes also increased [3]. Nakao et al. (1988), Saksena and Zydney (1994), Balakrishnana and Agarwal (1996), Lucas et al. (1998) and Burns and Zydney (1999) reported maximum protein transmission at the isoelectric point of the protein [4-7]. Several studies have also shown the importance of membrane surface charge characteristics on the high-resolution separation of proteins [8-10]. In these studies, reduced protein transmission rates were reported under conditions where the membrane and protein have similar charges, and were attributed to the resulting electrostatic repulsion between the protein and membrane. van Reis et al. (1999) have found higher selectivity for fractionation of BSA and Fab proteins by using charged membranes compared to neutral membranes [10].

In the literature different methods were proposed for placing a charge on the surface of ultrafiltration and reverse osmosis membranes, such as treatment with chemical reagents, irradiation [4,9,11-16] and proteins [17-19]. The layer-by-layer (LBL) assembly technique [20] was also used as an alternative method for creating either positively or negatively charged surfaces [21-23]. In this technique, a membrane with a charged surface is immersed in a solution of a macromolecule carrying opposite charges to those of the membrane surface. Commercial membranes with negative charges on their surface can be directly used $[24,25]$ or classical membranes such as polysulfone and polyacrylonitrile can be functionalized with charged groups by surface modification. Polyelectrolyte multilayer (PEM) show selective 
permeability for different species ranging from smaller ions to large molecules such as proteins. The permeability of these species through PEM depends on the porosity, thickness, and chemical composition of the layers, as well as the size and charge of the permeating species. Miller and Bruening (2005) prepared nanofiltration membranes with layer by layer deposition of hyaluronic acid-chitosan and reported the permeation of BSA and myoglobin through these membranes [21]. Aravind et al. (2007) and Mathew et al. (2008) modified commercial polyether sulfone microfiltration membrane with a uniform coating of chitosan/polystyrene sulfonate polyelectrolyte multilayer. They studied the transport of bovine serum albumin (BSA), ovalbumin and lysozyme through these membranes at their isoelectric points, as well as at pH levels below and above their isoelectric points. It was observed that the permeation characteristics of the proteins through the PEM-modified membranes depended on the number of deposited layers, as well as the $\mathrm{pH}$, concentration and ionic strength of the protein solution [22-23].

In this study, polyacrylonitrile (PAN) based ultrafiltration membranes were prepared, modified chemically and further modified with layer-by-layer (LBL) self assembly of a polyelectrolyte multilayer on the surface. Subsequently, their performances were evaluated in the ultrafiltration of two model proteins which have similar sizes, but different isoelectric points. PAN was chosen as a polymer to prepare the membranes due to its specific properties such as superior stirred for 24 hours to ensure complete dissolution. The solution was then heated shortly ( $5 \mathrm{~min}$ ) and cast on a glass support with the aid of an automatic film applicator (Sheen, Automatic film applicator-1133 N, Kingston, England) at a speed of $100 \mathrm{~mm} / \mathrm{sec}$. The wet thickness of the membrane was adjusted by a four-sided applicator with a gap size of $200 \mu \mathrm{m}$. Immediately after casting, the membranes were immersed into a coagulation bath which was placed in an environmental chamber maintained at $20{ }^{\circ} \mathrm{C}$. The coagulation medium contained $10 \mathrm{wt} \% \mathrm{Na}_{2} \mathrm{CO}_{3}$ prepared by dissolving the salt in ultra pure water. The membranes were kept in the coagulation bath for 24 hours. The following reaction is expected to take place between the coagulation bath and the casted membranes on glass plates:

$\mathrm{Na}_{2} \mathrm{CO}_{3}(\mathrm{aq})+\mathrm{CaCl}_{2} \rightarrow \mathrm{CaCO}_{3}(\mathrm{~s})+2 \mathrm{NaCl}(\mathrm{aq})$

After removal from the coagulation bath, the membranes were rinsed with ultra pure water to remove residual solvent, additive and $\mathrm{CaCO}_{3}$ precipitates. Until further use, the membranes were wet stored in a refrigerator.

\subsection{Surface modification of PAN membranes}

The chemical modification of PAN can be done easily by converting its $-\mathrm{CN}$ group into first $-\mathrm{CONH}_{2}$, then to $-\mathrm{COOH}$ groups as shown by the following reaction mechanisms:

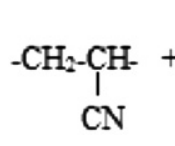

resistance to hydrolysis and oxidation, ease of surface modification, good solvent stability and low cost compared to other conventional polymers. The membranes were prepared by wet-phase inversion technique and polyethylenimine and alginate were chosen as cationic and anionic polyelectrolytes for the modification of the membrane surfaces. Sieving coefficient data were obtained with myoglobin and lysozyme as model proteins. The influences of solution $\mathrm{pH}$, ionic strengths of the protein and polyelectrolyte solution and the number of polyelectrolyte bilayers on both protein selectivity and throughput were investigated. In addition, the surface characteristics of the membranes such as acid-base functionality and hydrophilicity were determined.

\section{Materials and method}

\subsection{Materials}

Polyacrylonitrile, $\mathrm{CaCl}_{2}, \mathrm{Na}_{2} \mathrm{CO}_{3}, \mathrm{NaOH}$, sodium alginate (ALG) and $50 \mathrm{v} / \mathrm{v} \%$ polyethylenimine ( $\mathrm{PEI}, \mathrm{Mw}=750000 \mathrm{~g} / \mathrm{mole}$ ) were purchased from Sigma-Aldrich. Dimethyl formamide (DMF) and $37 \mathrm{wt} \%$ solution of $\mathrm{HCl}$ were obtained from Merck. Myoglobin and lysozyme were supplied by Sigma-Aldrich and Fluka-Biochemika, respectively. Solutions of these proteins were prepared by dissolving powdered myoglobin and lysozyme in phosphate buffer solution (PBS) prepared with $22 \mathrm{mM} \mathrm{Na}_{2} \mathrm{HPO}_{4}$ (Merck) and $\mathrm{Na}_{2} \mathrm{H}_{2} \mathrm{PO}_{4} \cdot \mathrm{H}_{2} \mathrm{O}$ (Merck) aqueous solutions. All aqueous solutions were prepared with milli-Q water $(>18 \mathrm{M} \Omega \mathrm{cm})$.

\subsection{Preparation of membranes}

To prepare casting solution, PAN powder was dissolved in a mixture of $3 \mathrm{wt} \% \mathrm{CaCl}_{2}$ salt and $85 \mathrm{wt} \% \mathrm{DMF}$ and the solution was

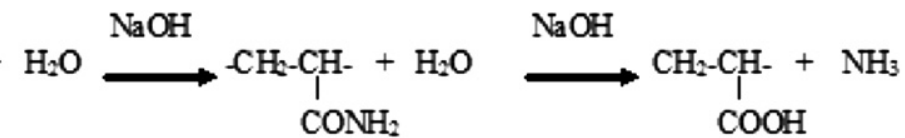

For modification, the PAN membranes were first immersed into a $2 \mathrm{M} \mathrm{NaOH}$ solution previously heated to $40{ }^{\circ} \mathrm{C}$. The solution containing the membranes was then left in a constantly shaking water bath at $40{ }^{\circ} \mathrm{C}$ for 1 hour until its color turned into a dark orange-red. The membranes were then rinsed with ultrapure water until neutral $\mathrm{pH}$ was reached and then immersed into an $\mathrm{HCl}$ solution of $0.1 \mathrm{~N}$ at room temperature for $30 \mathrm{~min}$. After re-rinsing with water until neutral $\mathrm{pH}$ was reached again, the samples were wet stored in a refrigerator. To avoid confusion, chemically-modified PAN membrane will be denoted as PAN-C.

\subsection{Deposition of polyelectrolytes on the surface of modified PAN membranes}

Chemically-modified PAN membrane (PAN-C), which became negatively charged after hydrolysis, was first dipped in a $1 \mathrm{~g} / \mathrm{L}$ of polycationic PEI solution for $30 \mathrm{~min}$. The $\mathrm{pH}$ of the PEI solution was adjusted by $\mathrm{HCl}$ to a value of 7 , under its isoelectric point, in order to obtain a sufficiently protonated form of the PEI to ensure its strong bonding on the negatively charged PAN-C surface through electrostatic attraction. To remove excessive PEI on the surface of the self-assembled layer, the membrane was rinsed with $250 \mathrm{ml}$ double-distilled water for $30 \mathrm{~min}$. Thereafter, the membrane was immersed in a $1 \mathrm{~g} / \mathrm{L}$ of polyanionic alginate solution at $\mathrm{pH} 7$ for $30 \mathrm{~min}$. Loosely-bound alginate on the surface was washed away under same conditions described above. To build successive polyelectrolyte bilayers, the dipping in alternating PEI and alginate solutions and rinsing after each removal were repeated until the desired number of bilayers was obtained. In order to investigate the effect of the ionic strength of the polyelectrolyte solution, the method described for forming the PAN-1b membrane was applied except that the ALG solution 
contained $0.1 \mathrm{M} \mathrm{NaCl}$ and the ultrafiltration experiments were repeated with this membrane.

\subsection{Ultrafiltration studies}

Permeability experiments were performed using a dead-end stirred-cell filtration system (Model 8010, Millipore Corp, Bedford,MA) with a total internal volume of $10 \mathrm{ml}$ and an active surface area of $4.1 \mathrm{~cm}^{2}$. The feed-side pressure was maintained by nitrogen at 0.3 bar. To avoid concentration polarization, the feed solution was continuously stirred with a speed of $600 \mathrm{rpm}$ [26]. To determine fouling tendency of the membranes, the cell was initially filled with water and the flux was measured. Then, the cell was emptied and refilled with a $0.5 \mathrm{mg} / \mathrm{ml}$ protein solution and the flux of the protein solution was measured. Finally, the cell was filled with water again and the flux was re-evaluated. Filtrate fluxes were measured at several transmembrane pressures and the hydraulic permeabilities of water through clean and protein filtrated membranes were determined. In all permeation experiments the system temperature was maintained at $23 \pm 2{ }^{\circ} \mathrm{C}$. The sieving coefficient data for lysozyme and myoglobin were obtained with clean membranes using PAN-C and PEI/ALG deposited PAN-C membranes. The molecular weight, size and isoelectric points of the two proteins are given in Table $1[27,28]$. Protein solutions were prepared with a concentration of $0.5 \mathrm{mg} / \mathrm{ml}$ in PBS solutions at $\mathrm{pH} 5,7$, and 11 . The ionic strength of the protein solution was adjusted as 0 and $0.1 \mathrm{M}$ by adding salt. Lysozyme and myoglobin concentrations were determined with a UV-vis spectrophotometer (Perkin Elmer, Model No: Lambda 45) at wavelengths of $280 \mathrm{~nm}$ and $410 \mathrm{~nm}$, respectively. The filtration data were presented in terms of selectivity and throughput. The dimensionless selectivity, $\psi$, is defined as [10]:

$\psi=S_{1} / S_{2}$

where $S_{1}$ and $S_{2}$ are the dimensionless observed sieving coefficients of the less and more retained proteins, respectively. The sieving coefficients were evaluated as the ratio of the protein concentration in the permeate to that in the bulk retentate solution.

A throughput parameter was calculated from the difference between the sieving coefficients [10]

$J \Delta S=J\left(S_{1}-S_{2}\right)$

where $J\left[\mathrm{~L} \mathrm{~m}^{-2} \mathrm{~h}^{-1}\right]$ is the filtrate flux.

\subsection{Surface characterization of the membranes}

Equilibrium sessile drop contact angles were determined from the steady-state angles which were reached between 30 and $120 \mathrm{~s}$ after the drop contacted the membrane surface. The measurements were carried out with Attension Optical tensiometer which records the drop images and analyzes with a drop-fitting profile. The volume of liquid drop varied between 3 and $5 \mu$ l. Each reported contact angle

Table 1

The molecular weight, size and isoelectric points of the lysozyme and myoglobin.

\begin{tabular}{lllll}
\hline Protein & $\begin{array}{l}\text { Molecular Weight } \\
\text { (g/mole) }\end{array}$ & $\begin{array}{l}\text { Isoelectric } \\
\text { Point }\end{array}$ & $\mathrm{pH}$ & $\begin{array}{l}\text { Hydrodynamic } \\
\text { Radius (nm) }\end{array}$ \\
\hline Myoglobin & 17800 & 7 & 5 & $>2.09,<2.32$ \\
& & & 7 & 2.09 \\
Lysozyme & 14700 & \multirow{2}{*}{11} & 11 & $<1.72$ \\
& & & 7 & 1.9 \\
& & & 11 & 2.2 \\
& & & 2.7 \\
\hline
\end{tabular}

value represents an average of at least ten sets of measurements. To determine the total surface free energy, $\gamma_{s}$, which is composed of dispersive $\left(\gamma_{d}\right)$ and polar components $\left(\gamma_{p}\right)$, contact angle measurements for three different liquids (distilled water, glycerol, and ethylene glycol) were carried out. The polar component can be divided into electron-donor (Lewis base), $\gamma_{i}^{-}$, and electron-acceptor (Lewis acid), $\gamma_{i}^{+}$, components. The total surface energy of the membrane is then defined as follows:

$\gamma_{s}=\gamma_{d}+\gamma_{p} \gamma_{p}=2 \sqrt{\gamma^{+} \gamma^{-}}$

In order to identify the change of surface charge of the membranes at different steps of the immobilization, a qualitative detection technique, specific staining of the membrane, was used. The carboxylic groups of the PAN-C and ALG-coated PAN-C membranes and the amine group of the PEI-coated PAN-C membranes were stained with cationic toluidine blue $\mathrm{O}$ and anionic congo red dyes, respectively. The membrane staining was performed by dipping the membrane in a $30 \mathrm{ppm}$ solution of the dye dissolved in its associated solvent for ca. $30 \mathrm{~min}$, followed by washing the sample with its solvent until the solvent became colorless. The amount of the charged groups on the membranes stained with dyes was determined spectrophotometrically in visible region (AventesAvemouse 62) in terms of intensity of the colors. Each intensity value represents an average of 10 measurements.

The surface morphology of the membranes was examined by scanning electron microscopy (Quanta 250 SEM). The samples were coated with gold using a Magnetron Sputter Coating Instrument.

\section{Result and discussion}

\subsection{Surface characterization of the PAN membranes}

Contact angles, acid-base surface tensions and total surface free energies of the uncoated and polyelectrolyte coated PAN membranes are given in Table 2 . The membranes coded as PAN-1b and PAN-5b correspond to one and five bilayer PEI/ ALG coated PAN-C membranes, respectively. The results in Table 2 illustrate that as the number of polyelectrolyte coating bilayers increased, the hydrophilic character of the membranes was improved, as confirmed by the drop in the water contact angle values. The total surface energy of all the membranes is mainly controlled by the van der Waals dispersive component. The modification of the PAN-C membrane with the polyelectrolyte coating increased its electron-donor functionality. The electron acceptor (acidic) functionalities of all the membranes are higher than their electron donor (basic) functionalities. This indicates that the negatively charged groups on the surface are in excess amount. The surface charge of the membranes was also determined with the staining technique described above. Fig. 1 shows the intensity of blue and red colors resulting from adsorption of cationic toluidine blue o and anionic congo red dyes. It is observed that the PAN-C and the polyelectrolyte coated PAN-C membranes (PAN-1b and PAN-5b) were more intensely stained by the blue color which indicates that the net surface charge of these membranes is negative. This result confirms that the polyelectrolytes were successfully immobilized on the PAN-C surface and charge inversion occurred during each dipping step into the polyelectrolyte solution. Small standard deviations in the intensity of each color shown in Fig. 1 indicate that both negatively and positively charged groups on chemically and LBL modified membranes (PAN-1b and PAN-5b) are almost homogeneously distributed on the surfaces.

Fig. 2 shows ESEM images of the PAN-C and the 5-bilayer PEI/ALG coated PAN-C membranes. As seen from the pictures, bulk structures of the both membranes have a dense skin layer at the top and large finger-like pores in the

Table 2

The dispersive $\left(\boldsymbol{\gamma}^{\mathbf{d}}\right)$, acidic $\left(\boldsymbol{\gamma}^{+}\right)$and basic components $\left(\boldsymbol{\gamma}^{-}\right)$of the surface free energy for the studied PAN membranes as calculated by the Van Oss approach.

\begin{tabular}{lllll}
\hline $\begin{array}{l}\text { Code of the } \\
\text { Membrane }\end{array}$ & $\gamma^{\mathrm{d}}\left(\mathrm{mJ} / \mathrm{m}^{2}\right)$ & $\gamma^{+}\left(\mathrm{mJ} / \mathrm{m}^{2}\right)$ & $\gamma^{-}\left(\mathrm{mJ} / \mathrm{m}^{2}\right)$ & $\begin{array}{l}\text { Water Contact } \\
\text { Angle (deg.) }\end{array}$ \\
\hline PAN-C & 48.06 & 10.03 & 1.95 & 58 \\
PAN-1b & 33.80 & 14.06 & 8.23 & 46 \\
PAN-5b & 25.78 & 10.27 & 8.65 & 36 \\
\hline
\end{tabular}


sublayer (Figs. 2a and 2c). Polyelectrolyte multilayer deposited uniformly and the nanopores in this layer are still visible even after the 5-bilayer coating is applied (Figs. 2b and d). The pore sizes of the membranes were determined from the SEM images and predicted by combining Hagen Poisseuille's law of capillary flow [29]

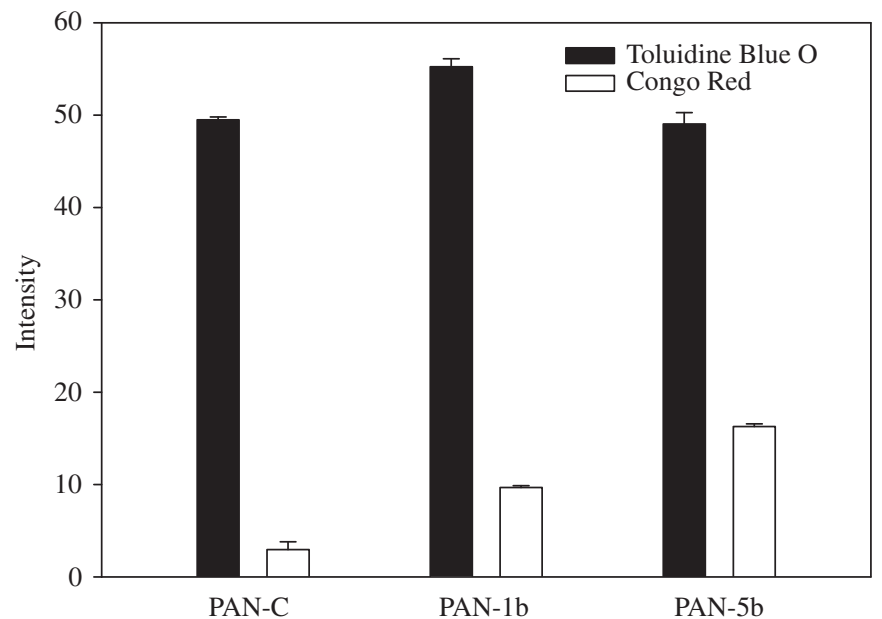

Fig. 1. Intensity of colors resulting from adsorption of cationic "Toluidine Blue O" and anionic "Congo Red" dyes on the unmodified and modified PAN membranes. and water flux $(J v)$ data collected at different transmembrane pressure $(\Delta \mathrm{P})$

$$
r_{p}=\left(\frac{8 J_{v} \mu L}{\pi N \Delta P}\right)^{1 / 4}
$$

where $r_{p}, N, \mu$ and $L$ represent the equivalent pore radius, number of pores, viscosity of water and the thickness of the dense skin layer, respectively. $N$ and $L$ values in the equation were determined from the SEM images. The pore sizes obtained from the SEM pictures and Hagen Poisseuille's law were found close to each other (Table 3) and the values are in agreement with those reported for the PAN membrane by Musale et al. [30]. The results show that the pore size of the PAN-C membrane was not significantly affected from the polyelectrolyte deposition which simply confirmed that polyelectrolytes did not penetrate into the membrane, instead, they adsorbed on the surface.

\subsection{The hydraulic permeability of water through clean and protein fouled PAN membranes}

The extend of irreversible protein fouling was assessed by the relative change in the hydraulic permeability of water before and after protein filtration. The filtration of myoglobin and lysozyme was carried out at $\mathrm{pH} 9$ which is close to their isoelectric points. Fig. 3 shows that after filtration of both proteins, a decrease in the hydraulic permeabilities of water through all the membranes was observed. The decrease is more pronounced in the case of lysozyme due to presence of an attractive interaction between the negatively-charged membranes and positively-charged lysozyme. The highest protein adsorption was observed on the uncoated and the most hydrophobic PAN-C membrane as a result of both electrostatic and hydrophobic interactions. Adding $0.1 \mathrm{M} \mathrm{NaCl}$ into the lysozyme solution decreased its adsorption on the PAN$1 \mathrm{~b}$ membrane, hence, reduced the drop in the hydraulic permeability caused by protein fouling. This can be explained by weaker electrostatic interactions between a

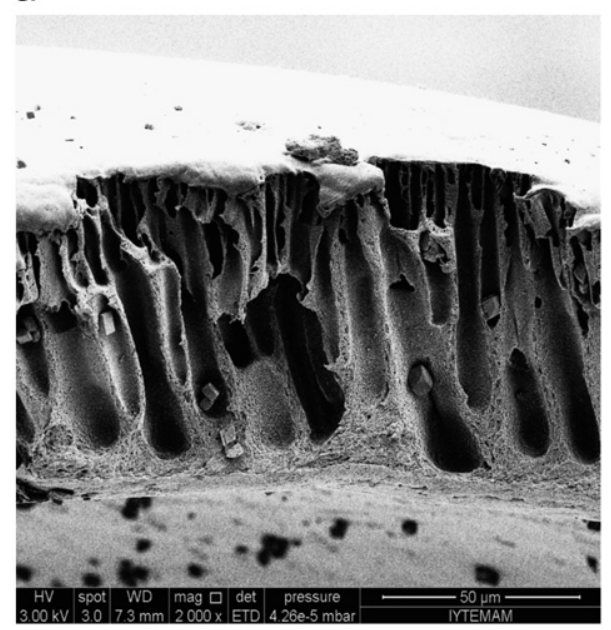

C

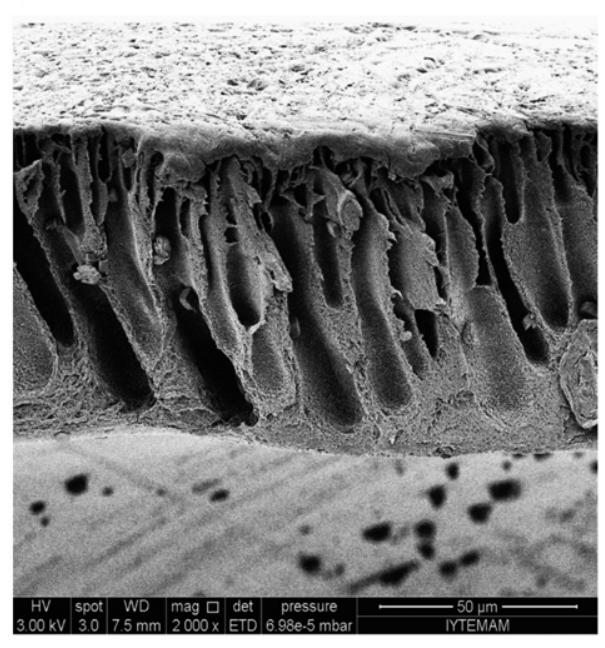

b

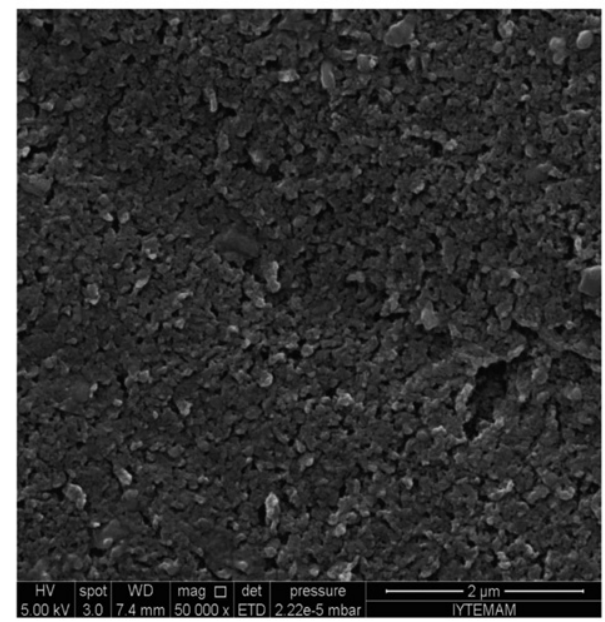

d

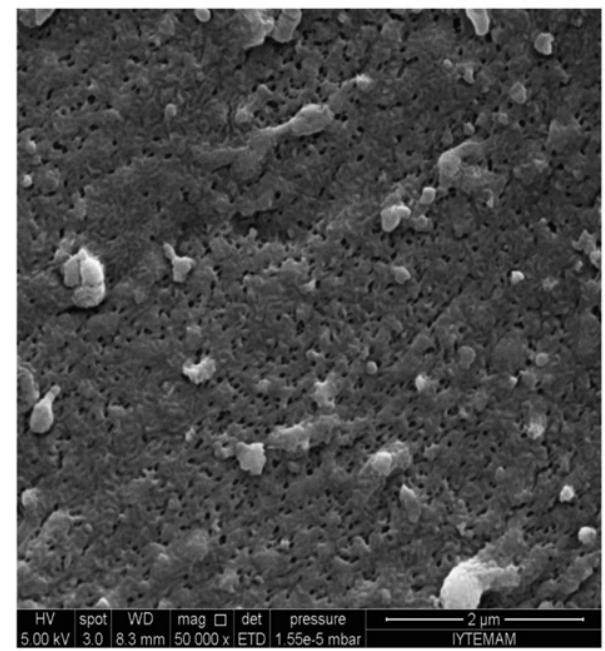

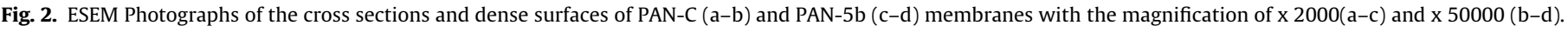


Table 3

The average pore size of the membranes determined from the SEM images and predicted from Hagen Poisseuille's law.

\begin{tabular}{lll}
\hline Code of the membrane & \multicolumn{2}{c}{ Average Pore Radius $(\mathrm{nm})$} \\
\cline { 2 - 3 } & SEM Images & $\begin{array}{l}\text { Hagen } \\
\text { Poisseuille's Law }\end{array}$ \\
\hline PAN-C & $22.4 \pm 7.5$ & 19.6 \\
PAN-1b & $19.9 \pm 5.7$ & 19.8 \\
PAN-5b & $18.7 \pm 5.3$ & 18.4 \\
\hline
\end{tabular}

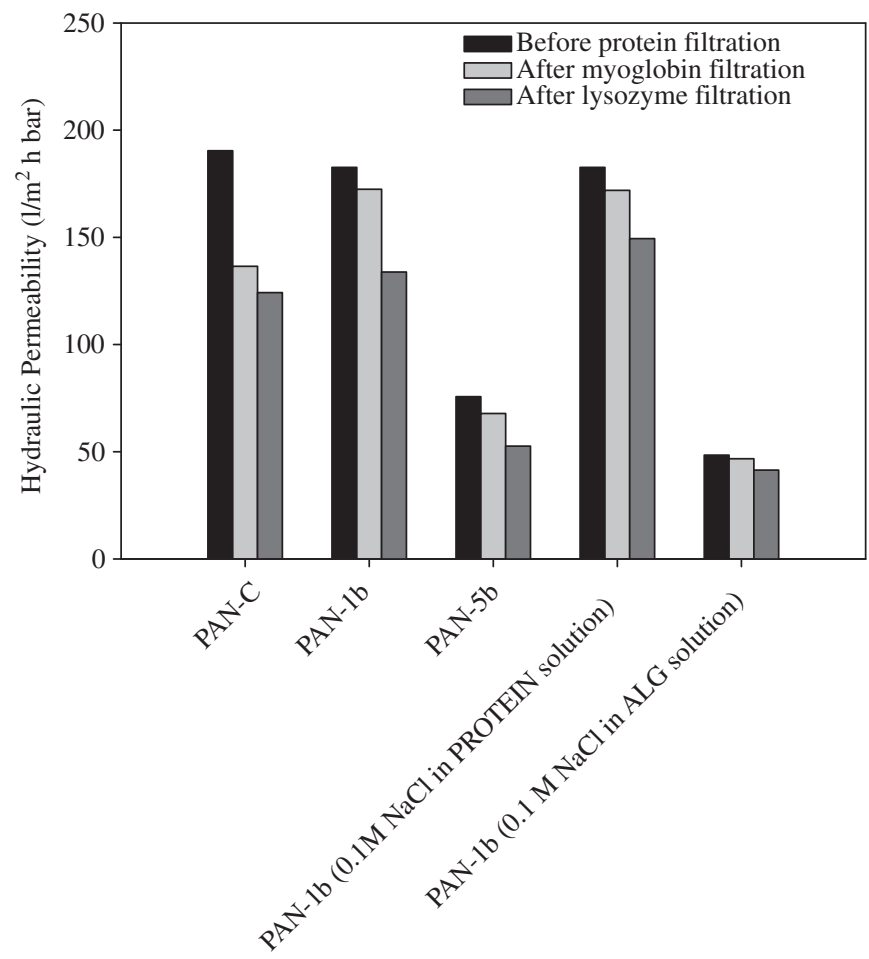

Fig. 3. The hydraulic permeability of water through clean and protein fouled PAN membranes.

the lysozyme and the membrane as a result of shielding provided by the bulk electrolyte and screening of the charges along the polyelectrolyte backbone of the membrane. The presence of salt in the alginate solution during preparation of the PAN-1b membrane decreased the charge density of alginate as confirmed by a drop in zeta potential of the solution from $-73.5 \mathrm{mV}$ to $-33.5 \mathrm{mV}$. Consequently, weaker electrostatic interactions between the proteins and alginate on the outermost surface of PAN-1b membrane reduced the adsorption of both proteins on the membrane, hence the drop in the hydraulic permeability of water due to protein fouling.

\subsection{Transport of proteins through the PAN membranes}

\subsubsection{Effect of $\mathrm{pH}$}

The solution $\mathrm{pH}$ is an important parameter for the ultrafiltration of proteins through charged membranes $[2,17,22,23,31,32]$. The electrical charge on both the protein and the membrane changes with $\mathrm{pH}$ due to acidic/basic groups on the protein and the membrane surfaces. These groups ionize and cause either attractive or repulsive interactions to occur [17]. Figs. 4 and 5 show experimental data for the observed sieving coefficients of myoglobin and lysozyme through chemically and LBL modified membranes as a function of $\mathrm{pH}$. The maximum observed sieving coefficient of myoglobin through all the membranes was obtained at $\mathrm{pH} 7$, which corresponds to the isoelectric point (iep) of the myoglobin. The occurrence of the highest protein transmission near the iep of the proteins was also reported by other researchers [4-7], and this was attributed to the absence of any significant electrostatic interactions when the charge of the protein is zero. In case of the $\mathrm{pH}<\mathrm{iep}(\mathrm{pH} 5)$ and $\mathrm{pH}>$ iep $(\mathrm{pH}$ 11), the transmission of myoglobin is lower than that at the iep due to the attraction (adsorption) and repulsion effects at these pHs, respectively. The net charge on both

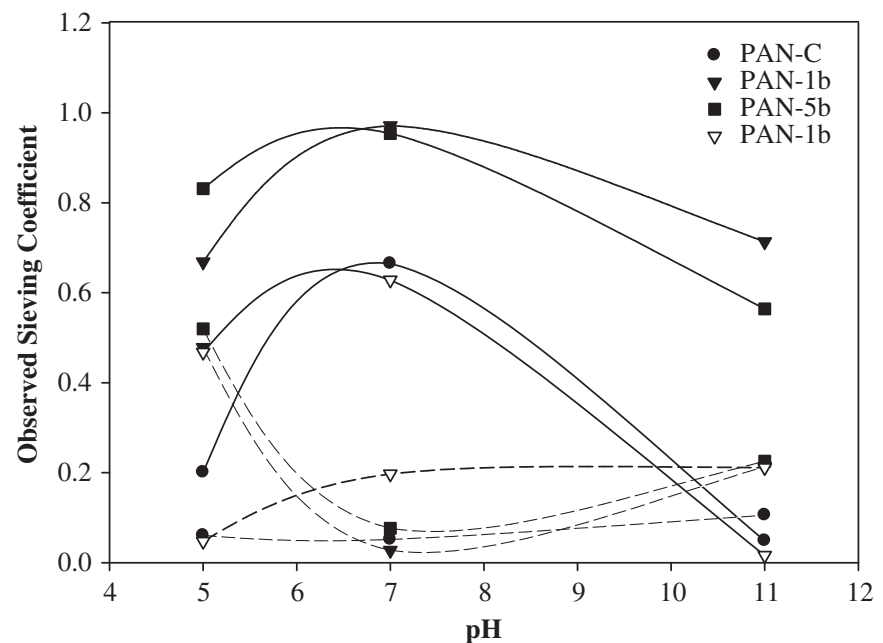

Fig. 4. Sieving coefficients of myoglobin (solid line) and lysozyme (dashed line) through the PAN-C and polyelectrolyte coated PAN-C membranes. Open and solid triangles correspond to the sieving coefficients of the proteins through one-bilayer polyelectrolyte coated PAN-C membrane with and without addition of $0.1 \mathrm{M} \mathrm{NaCl}$ to the alginate solution, respectively. Ionic strength of the protein solution is zero.

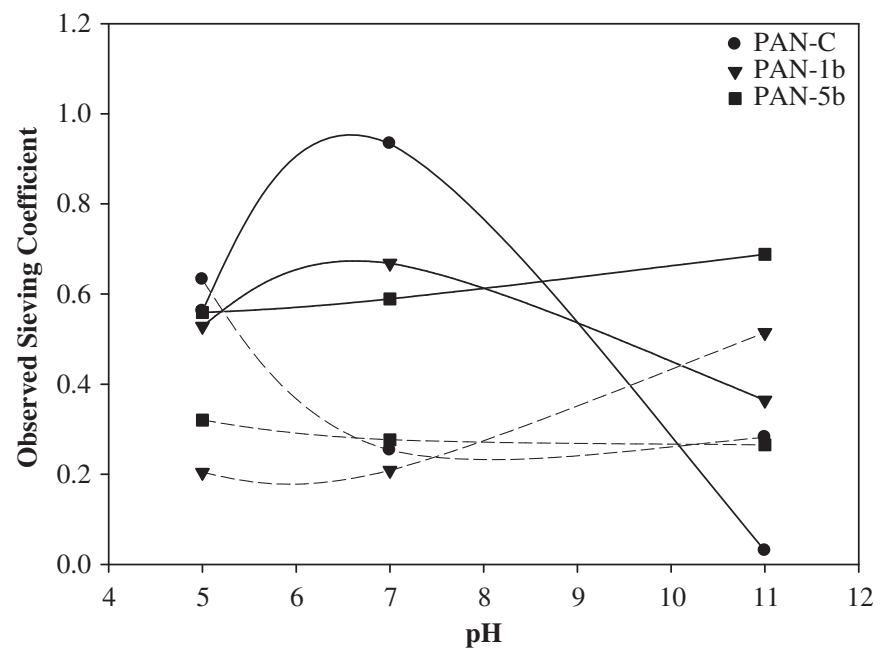

Fig. 5. Sieving coefficients of myoglobin (solid line) and lysozyme (dashed line) through the PAN-C and polyelectrolyte coated PAN-C membranes. Ionic strength of the protein solution is $0.1 \mathrm{M} \mathrm{NaCl}$.

the chemically and LBL modified membranes were found to be negative by the staining technique. When myoglobin is ultrafiltered at $\mathrm{pH} 5$, the positively-charged myoglobin molecules are attracted and adsorbed by the negatively charged membrane surfaces, and, consequently, a positively charged, self-rejecting layer forms on the surfaces. The long-range electrostatic repulsion effect that occurs between this self-rejecting layer and the myoglobin in the solution causes a decrease in the transmission. During ultrafiltration at $\mathrm{pH} \mathrm{11,} \mathrm{both} \mathrm{the} \mathrm{surfaces} \mathrm{of} \mathrm{the} \mathrm{membranes} \mathrm{and}$ the myoglobin are negatively charged. Thus, only a small amount of myoglobin can reach the membrane surface and permeate due to the strong electrostatic repulsion that exists [33]. At each $\mathrm{pH}$, the observed sieving coefficients of myoglobin through PEI-ALG coated PAN-C membranes are higher than that through the PAN-C membrane. The increase in the transmission can be explained by the improvement in hydrophilicity of the LBL modified membranes, as demonstrated by the decrease in their water contact angle values. Consequently, the polyelectrolyte-coated PAN-C membranes exhibited relatively lower fouling than the uncoated PAN-C membrane as shown in Fig. 3. Fig. 4 shows that the highest transmission of lysozyme through the PAN-C membrane was obtained at its iep ( $\mathrm{pH}=11)$. At the lower $\mathrm{pHs}(\mathrm{pH} 5$ and $\mathrm{pH} 7)$, lysozyme is positively charged and electrostatically attracted by the negatively charged membrane, resulting a decrease in transmission. For LBL modified membranes, the highest sieving coefficient was observed at $\mathrm{pH} 5$ where lysozyme has the minimum effective hydrodynamic radius [28]. This result indicates that sieving was an important factor, along with the electrostatic interaction, in the transmission of lysozyme through PEI-ALG coated PAN-C membranes. 


\subsubsection{Effect of ionic strength of the protein solution on protein transport}

In previous studies, ionic strength was found to be an important factor that may influence the transport behavior of proteins through the membranes $[2,23,31,32]$. Based on this fact, the ultrafiltration experiments were repeated with protein solutions containing $0.1 \mathrm{M} \mathrm{NaCl}$. The observed sieving coefficients of both myoglobin and lysozyme under this new condition are illustrated in Fig. 5. As expected, the transmissions of both myoglobin and lysozyme through chemicallymodified, negatively charged PAN-C membrane increased with the increase in ionic strength. This is attributed to the fact that, in the presence of salt the hydrophobic interactions between proteins and membrane can be decreased while the intra-hydrophobic interactions of the protein molecules can be significantly enhanced [34], moreover, the enlarged conformation of charged proteins becomes more compact due to the effect of ionic shielding [1,26,35-37]. Additionally, the increase in ionic strength of the protein solution causes weakening of the electrostatic interaction between the protein and membrane, since the $\mathrm{Na}^{+}$and $\mathrm{Cl}^{-}$ions decrease the activity coefficient of protonation at $\mathrm{pH}$ below the isoelectric points of myoglobin and lysozyme [32].

As for the polyelectrolyte-coated PAN membranes, the sieving coefficients of both proteins decreased with the increase in ionic strength via the addition of salt to the protein solution. Although the charges along the polyelectrolyte backbone of the PAN-1b membrane could be screened in the presence of salt, the decrease in the sieving coefficients may be the result of the conformational change of the polyelectrolyte layers when the ionic strength is increased [38]

\subsubsection{The effect of salt addition to polyelectrolytes}

Previous studies on polyelectrolyte multilayer formation have reported that the ionic strength of the polyelectrolyte solution has an effect on the configuration of the polyelectrolyte chains in solution. Adsorption of the chains in a particular configuration controls the thickness and porosity of the multilayer structure being determined by the strength and range of the intra and intermolecular electrostatic interactions $[22,37,39]$. Fig. 4 shows that the sieving coefficient of myoglobin (open triangles) through the membrane prepared with addition of salt into the ALG solution was found to be lower. This is due to the fact that, in the presence of salt, the total amount of deposited polyelectrolyte and, thus, the layer thickness increases as a result of the weaker intra molecular repulsion [22,37]. In the case of lysozyme, the addition of salt to the polyelectrolyte solution doesn't change its sieving efficiency through the

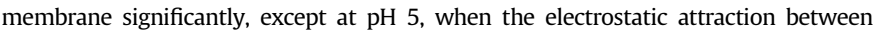
the lysozyme and the membrane surface is at a maximum and the hydrodynamic radius of the lysozyme is at a minimum [28]. As the $\mathrm{pH}$ approaches the iep of lysozyme, the electrostatic interactions become weaker and, hence, the transport of lysozyme through the two different types of polylelectrolyte deposited membranes becomes similar.

\subsubsection{Effect of number of bilayers}

In order to analyze the effect of the number of bilayers on the protein separation process in detail, ultrafiltration experiments were conducted where the number of polyelectrolyte coating bilayers on the PAN-C membrane was incrementally increased from 0.5 to 5 . It should be noted that one bilayer represents PEI/ALG coating while the 0.5 bilayer corresponds to just PEI coating on the PAN-C membrane. Other odd number of bilayers $(1.5,2.5)$ were constructed by subsequent deposition of PEI on the PEI/ALG bilayer. The transport of both proteins was carried out at $\mathrm{pH} 9.0$,

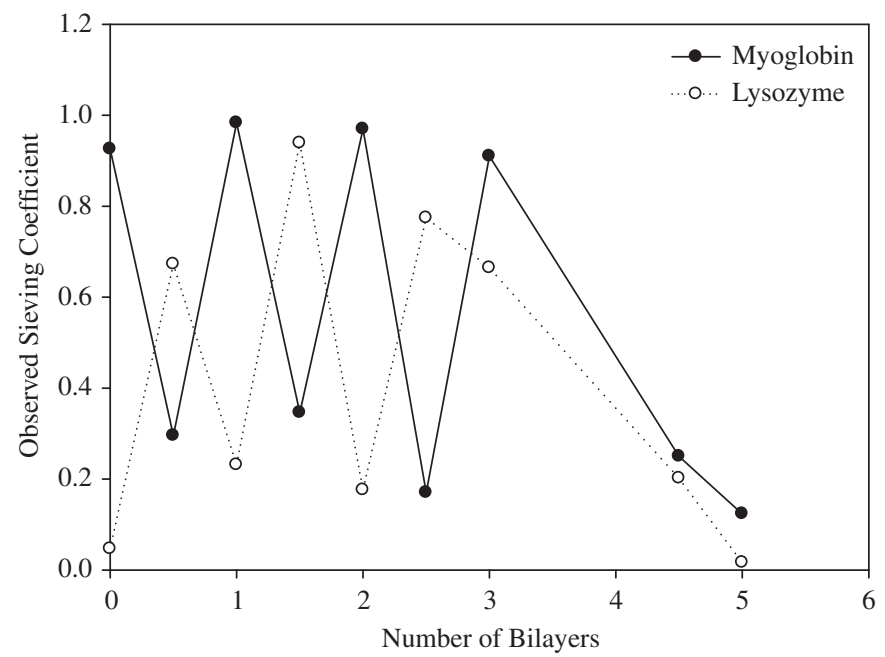

Fig. 6. Sieving coefficients of myoglobin and lysozyme through the PEI-ALG coated PAN-C membranes with respect to number of bilayers. Open and solid symbols represent odd (the PEI is the outermost layer) and even (the ALG is the outermost layer) number of bilayers, respectively. which is close to iep of lysozyme (11) and myoglobin (7). The observed sieving coefficients through uncoated and polyelectrolyte coated PAN-C membranes are shown in Fig. 6. Because ALG forms the last layers of the 1, 2, 3, 4, and 5-bilayer coated membranes, their surfaces are negatively charged, whereas for the $0.5,1.5$ 2.5, and 3.5-bilayer coated PAN-C membranes (where the PEI is the last layer), the membrane surfaces are positive. The results in Fig. 6 show that when the membrane and protein are oppositely charged, the permeation of both proteins through the membranes is lower than the case when they are similarly charged. This is due to the adsorption of the proteins on the membrane surface and the concentration polarization. In the case when the protein and membrane are similarly charged, it is normally expected that the electrostatic repulsion between the two will be large enough to result in a lowering of the sieving coefficients. In fact, we have observed that the sieving coefficients of both proteins through the membrane are higher when the protein and membrane are of the same charge. This occurs, because at $\mathrm{pH}$ close to iep, the positive charge on lysozyme and negative charge on myoglobin are not high enough to significantly reject the proteins from the similarly charged membrane surface. This result is supported by the previous findings shown in Figs. 4 and 5 that the highest sieving coefficient for each protein was obtained at its iep. Finally, it was observed that the sieving coefficients of both myoglobin and lysozyme decreased significantly through PAN $\mathrm{C}$ membranes that were coated with more than 3 PEI-ALG bilayers. This indicates mass transfer resistance to the permeation of proteins through the membranes which increases with the thickness of the polyelectrolyte layer deposited.

\subsection{Separation of proteins}

Figs. 7a and 7b show selectivity and throughput values as a function of $\mathrm{pH}$ for ionic strengths of the protein solution zero $(I S=0)$ and $0.1 \mathrm{M}(I S=0.1 \mathrm{M} \mathrm{NaCl})$. The selectivity is defined as the ratio of sieving coefficient of myoglobin to that of lysozyme. For all the cases, the maximum selectivity and throughput values were obtained at $\mathrm{pH} \mathrm{7,} \mathrm{which} \mathrm{is} \mathrm{the} \mathrm{isoelectric} \mathrm{point} \mathrm{of} \mathrm{myoglobin.} \mathrm{The} \mathrm{highest}$ selectivity and throughput were achieved with the 1-bilayer PEI-ALG coated PAN-C membrane (PAN-1b). When the membrane and protein are oppositely charged, increasing the number of coating bilayers from 1 to 5 decreased both the maximum selectivity and throughput of the membrane; however, the values are still higher than those for the chemically-modified PAN membrane. Furthermore addition of salt to the protein solution also decreased both the maximum selectivity and throughput of the membranes. Previously, the separation of lysozyme from myoglobin has been investigated by a few groups. Müller et al. [40] reported the maximum selectivity of lysozyme against myoglobin through cellulose acetate membrane around 3 at pH 7, low transmembrane pressure and zero ionic strength of the protein solution. For similar conditions, we have determined the selectivity value of 36 through the 1-bilayer PEI-ALG coated PAN-C membrane. The efficiencies of surface modified PAN and polyethersulfone (PES) membranes were also tested at $\mathrm{pH} 7$ and the ionic strength of 0.15 and $0.1 \mathrm{M}$ $\mathrm{NaCl}$, respectively [41,42]. The selectivities of lysozyme against myoglobin through these membranes were determined as 2.5-3 which are almost 4 times lower than that obtained in our study with the PAN-1b membrane. Compared with the performances of the existing membranes reported in the literature, it can be said that lysozyme/myoglobin separation can be achieved more successfully through the 1-bilayer PEI-ALG coated PAN-C membrane prepared in this study. Figs. 7a and 7b illustrate that both the selectivity and throughput are lower for 1-bilayer coated membrane prepared from polyelectrolyte solution containing salt compared with those of the uncoated PAN-C membrane and the 1-bilayer membrane coated with salt-free polyelectrolyte solution. This occurs because the salt addition to the polyelectrolyte solution increases the amount of adsorbed polyelectrolyte, thus, the thickness of the polyelectrolyte layer. The results in Fig. 7 suggest that it is possible to increase the performance of the PAN-C membrane for separating myoglobin from lysozyme by adding just one bilayer of PEI-ALG coating and adjusting the $\mathrm{pH}$ of the protein solution to the isoelectric point of the protein, resulting in a higher sieving coefficient.

Effective protein separation in ultrafiltration process requires high values of both selectivity and throughput, in order to obtain the optimum combination of process yield and purification factor. The selectivity determines the separation capacity of the membrane while throughput is related with the practical limits on the process. Based on maximum throughput and selectivity values, it is possible to determine the limit of the pressure that can be applied through the membrane. The combination of these two values also provides an opportunity for selecting suitable module size (which determines the membrane area) to conduct effective separation. Separation factor determined from a single protein data and binary protein mixtures may exhibit differences since the attractive electrostatic interaction in the presence of oppositely charged proteins both in bulk and in polarized layer may hinder the protein transmission. In addition, increased competition between the proteins for entering into pores may alter the selectivity. On the other hand, studies in literature indicate that under conditions of low transmembrane pressure and high mass transfer rates, transmission characteristics of dilute protein mixtures are almost identical to those of corresponding single protein measurements $[41,43-44]$. Based on these findings it can be suggested that the 
a

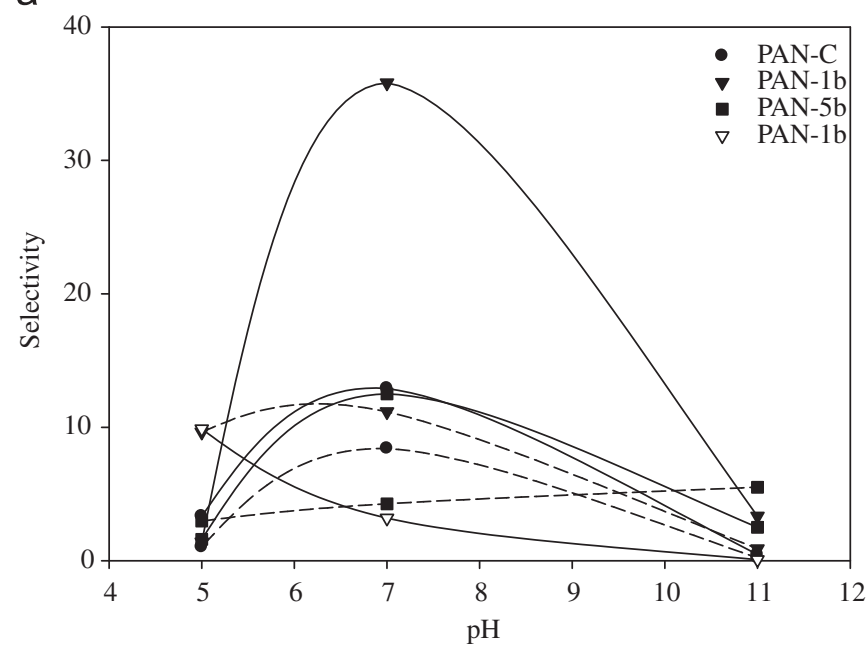

$\mathrm{b}$

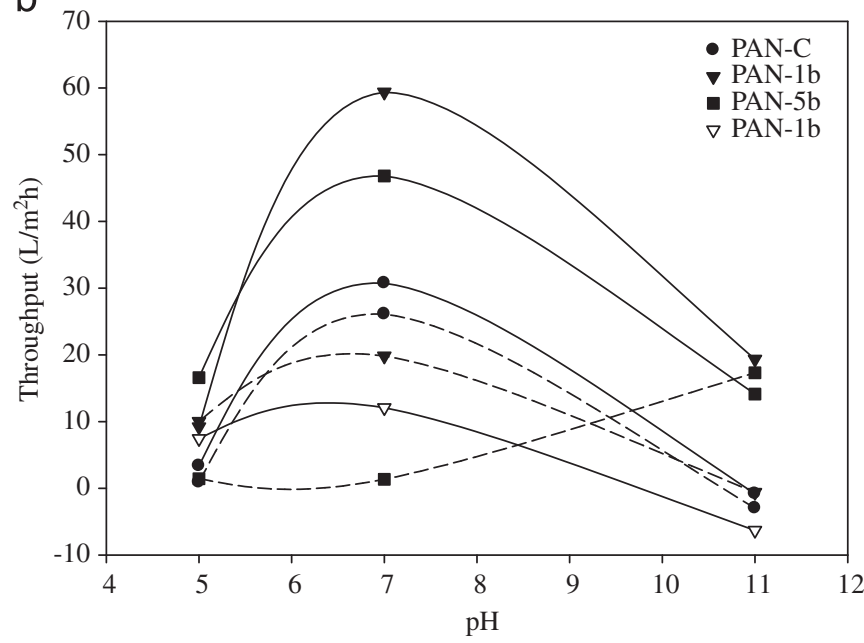

Fig. 7. The influence of $\mathrm{pH}$ on (a) selectivity and (b) throughput of PAN membranes for the ionic strength of the protein solution of 0 (solid line) and $0.1 \mathrm{M} \mathrm{NaCl}$ (dashed line). Open and solid triangles correspond to the data for onebilayer polyelectrolyte coated PAN-C membrane with and without addition of $0.1 \mathrm{M} \mathrm{NaCl}$ to the alginate solution, respectively.

separation factor determined in this study from single protein measurements can be used for an actual separation of dilute mixture of lysozyme and myoglobin.

\section{Conclusion}

The data in this study demonstrate that the hydrophilicity and separation characteristics of the PAN membranes can be modified with the deposition of a PEI/ALG polyelectrolyte bilayer. The protein adsorption capacity of the chemically-modified PAN-C membrane was reduced with the polyelectrolyte deposition. The maximum sieving coefficients of myoglobin through all the membranes was observed at its isoelectric point. The lysozyme attained its maximum sieving coefficient at its iep only through chemically-modified PAN-C membrane. For polyelectrolyte coated membranes, the maximum was observed at $\mathrm{pH} 5$, where lysozyme has the minimum effective hydrodynamic radius. The transmissions of both proteins through chemically-modified, negatively charged PAN-C membrane increased with the ionic strength of the protein solution, while an opposite trend was observed in the case of the LBL modified membranes. Adding salt to the polyelectrolyte solution affected the sieving performance of the LBL modified membranes negatively. Also, it was observed that the sieving coefficients of both proteins were higher when the membrane carried the same charge as the protein compared to when they were of opposite charge. The highest selectivity and throughput were achieved with the 1 bilayer PEI-ALG coated PAN-C membrane (PAN-1b). The results shown in this study suggest that self assembly of the polyelectrolytes on the membrane surfaces opens up new opportunities for adjusting electrostatic interactions and, hence, allows improvement of the sieving characteristics of these membranes in separating similar sized proteins.

\section{Acknowledgments}

The authors would like to thank Izmir Institute of Technology for the financial support through Grant 2009iYTE01. We also gratefully acknowledge Izmir Institute of Technology, Biotechnology and Bioengineering Research and Application Center for providing ultrafiltration experimental setup.

\section{References}

[1] N.S. Pujar, A.L. Zydney, Electrostatic and electrokinetic interactions during protein transport through narrow pore membranes, Ind. Eng. Chem. Res. 33 (1994) 2473-2482.

[2] S. Saksena, A.L. Zydney, Effect of solution pH and ionic strength on the separation of albumin from immunoglobulins ( $\operatorname{IgG}$ ) by selective filtration, Biotechnol. Bioeng. 43 (1994) 960-968.

[3] M. Rabiller-Baudary, B. Chaufer, D. Lucas, F. Michel, Ultrafiltration of mixed protein solutions of lysozyme and lactoferrin: role of modified inorganic membranes and ionic strength on the selectivity, J. Membr Sci. 184 (2001) 137-148.

[4] S. Nakao, H. Osada, H. Kurata, T. Tsuru, S. Kimura, Separation of proteins by charged ultrafiltration membranes, Desalination 70 (1988) 191-205.

[5] M. Balakrishnan, G.P. Agarwal, Protein fractionation in a vortex flow filter I: Effect of system hydrodynamics and solution environment on single protein transmission, J. Membr. Sci. 112 (1996) 47-76.

[6] D. Lucas, M. Rabiller-Baudry, F. Michel, B. Chaufer, Role of the physicochemical environment on ultrafiltration of lysozyme with modified inorganic membrane, Colloids Surf., A 136 (1998) 109-122.

[7] D.B. Burns, A.L. Zydney, Effect of solution $\mathrm{pH}$ on protein transport through semipermeable ultrafiltration membranes, Biotechnol. Bioeng. 64 (1999) 27-37.

[8] H. Miyama, H. Yoshida, Y. Nosaka, H. Tanzawa, Negatively charged polyacrylonitrile graft copolymer membrane for permeation and separation of plasma proteins, Macromol. Rapid Commun. 9 (1988) 57-61.

[9] L. Millesime, C. Amiel, B. Chaufer, Ultrafiltration of lysozyme and bovine serum albumin with polysulphone membranes modified with quaternized polyvinylimidazole, J. Membr Sci. 89 (1994) 223-234.

[10] R. van Reis, J.M. Brake, J. Charkoudian, D.B. Burns, A.L. Zydney, Highperformance tangential flow filtration using charged membranes, J. Membr Sci. 159 (1999) 133-142.

[11] L. Millesime, J. Dulieu, B. Chaufer, Fractionation of proteins with modified membranes, Bioseparation 6 (1996) 135-145.

[12] A. Higuchi, S. Mishima, T. Nakagawa, Separation of proteins by surface modified polysulfone membranes, J. Membr. Sci. 57 (1991) 175-185.

[13] J. Randon, P. Blanc, R. Paterson, Modification of ceramic membrane surfaces using phosphoric acid and alkyl phosphonic acids and its effect on ultrafiltration of BSA protein, J. Membr. Sci. 98 (1995) 119-129.

[14] D. Mukherjee, A. Kulkarni, W.N. Gill, Flux enhancement of reverse-osmosis membranes by chemical surface modification, J. Membr. Sci. 97 (1994) 231-249.

[15] S. Mok, D.J. Worsfold, A. Fouda, T. Matsuura, Surface modification of polyethersulfone hollow-fiber membranes by gamma-ray irradiation, J. Appl. Polym. Sci. 51 (1994) 193-199.

[16] N. Ehsani, S. Parkkinen, M. Nyström, Fractionation of natural and model egg-white protein solutions with modified and unmodified polysulfone UF membranes, J. Membr. Sci. 123 (1997) 105-119.

[17] R. Ghosh, Z.F. Cui, Fractionation of BSA and lysozyme using ultrafiltration: effect of pH and membrane pretreatment, J. Membr. Sci. 139 (1998) 17-28.

[18] S. Nakatsuka, A.S. Michaels, Transport and separation of proteins by ultrafiltration through sorptive and non-sorptive membranes, J. Membr. Sci. 69 (1992) 189-211.

[19] R.H.C.M. van Eijndhoven, S. Saksena, A.L. Zydney, Protein fractionation using electrostatic interactions in membrane filtration, Biotechnol. Bioeng. 48 (1995) 406-414.

[20] G. Decher, J.D. Hong, J. Schmitt, Buildup of ultrathin multilayer films by a selfassembly process: III, Consecutively alternating adsorption of anionic and 
cationic polyelectrolytes on charged surfaces 210-211 (1992) 831-835Thin Solid Films 210-211 (1992) 831-835.

[21] M.D. Miller, M.L. Bruening, Correlation of the swelling and permeability of polyelectrolyte multilayer films, Chem. Mater. 17 (2005) 5375-5381.

[22] U.K. Aravind, J. Mathew, C.T. Aravindakumar, Transport studies of BSA, lysozyme and ovalbumin through chitosan/polystyrene sulfonate multilayer membrane, J. Membr. Sci. 299 (2007) 146-155.

[23] J. Mathew, C.T. Aravindakumar, U.K. Aravind, Effect of ionic strength and protein concentration on the transport of proteins through chitosan/polystyrene sulfonate multilayer membrane, J. Membr. Sci. 325 (2008) 625-632.

[24] J. Kochan, T. Wintgens, J.E. Wong, Polyelectrolyte-modified polyethersulfone ultrafiltration membranes for wastewater treatment applications, Desalination Water Treat. 9 (2009) 175-180.

[25] J. Kochan, T. Wintgens, J.E. Wong, Properties of polyethersulfone ultrafiltration membranes modified by polyelectrolytes, Desalination 250 (2010) 1008-1010.

[26] M.K. Menon, A.L. Zydney, Effect of ion binding on protein transport through ultrafiltration membranes, Biotech. Bioengineer. 63 (1999) 298-307.

[27] N. Hirota, Y. Kumaki, T. Narita, J.P. Gong, Y. Osada, Effect of charge on protein diffusion in hydrogels, J. Phys. Chem. B 104 (2000) 9898-9903.

[28] A. Bonincontro, A. De Francesco, G. Onori, Influence of $\mathrm{pH}$ on lysozyme conformation revealed by dielectric spectroscopy, Colloids Surf., B 12 (1998) 1-5.

[29] V. Smuleac, D.A. Butterfield, D. Bhattacharyya, Layer-by-layer-assembled microfiltration membranes for biomolecule immobilization and enzymatic catalysis, Langmuir 22 (2006) 10118-10124.

[30] D.A. Musale, A. Kumar, G. Pleizier, Formation and characterization of poly(acrylonitrile)/Chitosan composite ultrafiltration membranes, J. Membr. Sci. 154 (1999) 163-173.

[31] D.B. Burns, A.L. Zydney, Buffer effects on the zeta potential of ultrafiltration membranes, J. Membr. Sci. 172 (2000) 39-48.

[32] M.M. Rohani, A.L. Zydney, Role of electrostatic interactions during protein ultrafiltration, Adv. Colloid Interface Sci. 160 (2010) 40-48.

[33] M.C. Yang, W.C. Lin, Ultrafiltration of myoglobin using surface-sulfonated polysulfone hollow fiber, J. Polym. Res. 9 (2002) 61-67.
[34] S. Çete, E. Turan, E. Yıldırım, T. Çaykara, Myoglobin adsorption onto poly (glycidyl methacrylate) microbeads with surface functionalized iminodiacetic acid, Mater. Sci. Eng, C 29 (2009) 20-24.

[35] M. Sbai, P. Fievet, A. Szymczyk, B. Aoubiza, A. Vidonne, A. Foissy, Streaming potential, electroviscous effect, pore conductivity and membrane potential for the determination of the surface potential of a ceramic ultrafiltration membrane, J. Membr. Sci. 215 (2003) 1-9.

[36] J. Ruths, F. Essler, G. Decher, H. Riegler, I. Polyelectrolytes., Polyanion/ polycation multilayers at the air/monolayer/water interface as elements for quantitative polymer adsorption studies and preparation of hetero-superlattices on solid surfaces, Langmuir 16 (2000) 8871-8878.

[37] D. Guzey, D.J. McClements, Formation, stability and properties of multilayer emulsions for application in the food industry, Adv. Colloid Interface Sci. 128-130 (2006) 227-248.

[38] M Schönhoff, Layered polyelectrolyte complexes: physics of formation and molecular properties, J. Phys.: Condens. Matter 15 (2003) 1781-1808.

[39] R. Steitz, V. Leiner, R. Siebrecht, R.V. Klitzing, Influence of the ionic strength on the structure of polyelectrolyte films at the solid:liquid interface, Colloids Surf. A163 (2000) 63-70.

[40] C.H. Müller, G.P. Agarwal, Th. Melin, Th. Wintgens, Study of ultrafiltration of a single and binary protein solution in a thin spiral channel module, J. Membr. Sci. 227 (2003) 51-69.

[41] M. Balakrishnan, G.P. Agarwal, Protein fractionation in a vortex flow filter. II: Separation of simulated mixtures, J. Membr. Sci. 112 (1996) 75-84.

[42] K.F. Md Yunos, R.W. Field, Rejection amplification in the ultrafiltration of binary protein mixtures using sandwich configurations, Chem. Eng. Process. 47 (2008) 1053-1060.

[43] S. Nakatsuka, A. Michaels, Transport and separation of proteins by ultrafiltration through sorptive and non-sorptive membranes, J. Membr. Sci. 69 (1992) 189-211.

[44] R. Shukla, M. Balakrishnan, G.P. Agarwal, Bovine serum albumin-hemoglobin fractionation: significance of ultrafiltration system and feed solution characteristics, Bioseparation 9 (2000) 7-19. 